\title{
Pneumothorax in Patients with Pulmonary Langerhans Cell Histiocytosis
}

\author{
E. Radzikowska ${ }^{1}$ (D) K. Błasińska-Przerwa ${ }^{2} \cdot$ E. Wiatr $^{1} \cdot$ I. Bestry $^{2} \cdot$ R. Langfort ${ }^{3} \cdot$ K. Roszkowski-Śliż $^{1}$
}

Received: 5 May 2018 / Accepted: 28 August 2018 / Published online: 5 September 2018

(c) The Author(s) 2018

\begin{abstract}
Introduction Pneumothorax often develops in pulmonary Langerhans cell histiocytosis (PLCH), but some patients take a long time to be correctly diagnosed.

Objectives This study assessed the frequency of pneumothorax in PLCH and analysed the role of chest computed tomography $(\mathrm{CT})$ in the prompt diagnosis.

Patients and material Of the 90 patients with PLCH seen from 2000 to 2015, 29 (32\%) had pneumothorax as the initial finding. In this group, 18 (62\%) patients were diagnosed within 1 month, whereas the diagnosis was delayed for 4-120 months in $11(38 \%)$ patients.

Results Patients who had pneumothorax as the initial sign of PLCH tended to be younger (mean age $27.7 \pm 7.92$ vs. $39.9 \pm 13.21$ years; $P=0.0001)$, male $(69 \%$ vs. $43 \% ; P=0.028)$, smoked less (mean pack/years $8.4 \pm 6.85$ vs. $19 \pm 17.16$; $P=0.003)$, and had a significantly lower mean FVC $(77.96 \pm 19.62$ vs. $89.47 \pm 21.86 \%$ pred.; $P=0.015)$ and $\mathrm{FEV}_{1}$ ( $68.6 \pm 19.93$ vs. $79.4 \pm 21.48 \%$ pred.; $P=0.03$ than patients who had no pneumothorax. Recurrent pneumothorax was diagnosed more frequently in the group with a delayed diagnosis $(82 \%$ vs. $39 \% ; P=0.02)$. CT was performed in all of the patients who were diagnosed promptly, but in none of the patients with a delayed diagnosis.

Conclusions Patients who had pneumothorax as the initial sign of PLCH were younger, more frequently men, and had greater respiratory impairment than those who had no pneumothorax. CT in patients with pneumothorax led to a correct diagnosis of this disease.
\end{abstract}

Keywords Histiocytosis · PLCH $\cdot$ Pulmonary function test · Computed tomography

\section{Abbreviations}

CT Computed tomography

$\mathrm{DL}_{\mathrm{CO}} \quad$ Diffusion lung capacity for carbon monoxide

FEV $_{1} \quad$ Forced expiratory volume in $1 \mathrm{~s}$

FVC Forced vital capacity

LCH Langerhans cell histiocytosis

MS LCH Multisystem Langerhans cell histiocytosis

$\mathrm{PaO}_{2} \quad$ Partial pressure of oxygen in the blood

PLCH Pulmonary Langerhans cell histiocytosis

E. Radzikowska

e.radzikowska@wp.pl

1 III Department of Lung Diseases, National Tuberculosis and Lung Diseases Research Institute, Plocka 26 st., 01-138 Warsaw, Poland

2 Radiology Department, National Tuberculosis and Lung Diseases Research Institute, Warsaw, Poland

3 Pathology Department, National Tuberculosis and Lung Diseases Research Institute, Warsaw, Poland
Pred. $\quad$ Predicted

RV Residual volume

TLC Total lung capacity

\section{Introduction}

Langerhans cell histiocytosis ( $\mathrm{LCH})$ is a rare disease caused by the proliferation of abnormal bone marrow-derived, CD1a-positive Langerhans cells, which infiltrate various organs [1, 2]. LCH lesions can be observed in multiple organs or a single organ, usually the skin, bone, lymph nodes, or lungs. Pulmonary Langerhans cell histiocytosis (PLCH) is a smoking-related disease characterised by the development of nodular and cystic lung lesions that predispose to pneumothorax [3-7]. It is a disease of young and middle-aged people, mainly smokers, and affects both sexes equally. The course of LCH is unpredictable, and ranges from spontaneous regression (particularly in adults with 
pulmonary involvement who quit smoking) and stabilisation with or without relapses to continuous progression despite aggressive chemotherapy [3-7].

Pneumothorax often develops in PLCH and is very suggestive of the disease $[8,9]$. Nevertheless, some patients are not diagnosed correctly or take a long time to be diagnosed. In PLCH, smoking cessation is the most important recommendation, and the value of a prompt diagnosis cannot be overestimated.

This study assessed the frequency of pneumothorax in PLCH and analysed these patients, focusing on delayed diagnosis and the role of high-resolution computed tomography (HRCT) in the prompt diagnosis of PLCH.

\section{Patients and Methods}

From 01 January 2000 to 31 December 2014, data on 90 patients with PLCH were collected from our database. Multisystem LCH was diagnosed in 20 (22\%) patients and isolated pulmonary disease was diagnosed in $70(78 \%)$ patients. Seventy-nine patients were diagnosed based on clinical and radiological findings and were confirmed by histological assessments of lung ( 70 cases) or bone ( 9 cases). In six patients, the diagnosis was established by the presence of more than 5\% CD1a-positive cells in bronchoalveolar lavage fluid, and in five patients, diagnosis was based on the characteristic clinical and radiological findings and the exclusion of other possible causes of pulmonary lesions. Twenty-nine (32\%) patients had pneumothorax as an initial sign of pulmonary lesions before diagnosis. Data were gathered on patient sex, age, smoking history, symptoms, episodes of pneumothorax, results of pulmonary function tests (PFTs), computed tomography (CT), other organ involvement, histological examination of samples, date of first symptom(s), date of diagnosis, and date of last visit. For patients with pneumothorax as a first sign of PLCH, pulmonary function tests (PFTs) were performed according to the joint guidelines of the American Thoracic Society and European Respiratory Society 3-6 months after the episode. The lung volumes were measured using body plethysmography (Jaeger MasterScreen software ver. 4.65; Würzburg; Germany) and the diffusion capacity of the lungs for carbon monoxide $\left(\mathrm{DL}_{\mathrm{CO}}\right)$ was determined using the single-breath technique. The predicted values were analysed.

Of patients with pneumothorax, 18 (62\%) were diagnosed within 1 month and made up the no-delay (ND) group, while the diagnosis was delayed for between 4 and 120 (mean $37.64 \pm 41.79)$ months in $11(38 \%)$ patients who made up the delayed (D) group.

First and second episodes of pneumothorax were treated by chest tube drainage, however, in some recurrent cases with pleurodesis. The persistent air leak and multiple pneumothoraces were indication for videoassisted thoracoscopy with pleurodesis.

\section{Statistical Methods}

The statistical analyses were performed using Statistica 10 (StatSoft, Tulsa, OK, USA). Continuous variables were compared using an unpaired Student's $t$ test or the Mann-Whitney $U$ test. Fisher's exact test and the $\chi^{2}$ test were used to assess proportions. $P$ values less than 0.05 were considered statistically significant. All $P$ values were two-sided and unadjusted for multiple testing.

\section{Results}

Table 1 summarises the characteristics of the study groups. One-third of patients with PLCH experienced spontaneous pneumothorax as the initial presentation of the disease. One patient initially had a bilateral pneumothorax. There were no significant differences in the distribution of patients with multisystem LCH between the two groups. Men (69\% vs. $43 \% ; P=0.028$ ) and young patients (mean age $27.7 \pm 7.92$ vs. $39.9 \pm 13.21$ years; $P=0.0001$ ) were overrepresented in the group of patients with pneumothorax as the first sign of PLCH. Only 2 of the 90 patients were non-smokers: a 15 -year-old boy with no significant exposure to cigarette smoke and a woman who was passively exposed to cigarette smoke. Patients who had pneumothorax at the presentation of the disease smoked less than those without it as the initial sign of PLCH (mean pack/years, $8.4 \pm 6.85$ vs. $19 \pm 17.16$; $P=0.003)$. Pneumothorax recurred in 19 patients (21\%), of whom 16 (55\%) had pneumothorax as the first sign of PLCH. In one patient with multisystem $\mathrm{LCH}$, recurrent pneumothorax was observed during the course of disease progression. Two other patients also had one recurrent pneumothorax each, also linked with disease progression. Patients who had pneumothorax as the first sign of PLCH had a significantly lower mean forced vital capacity (FVC) $(77.96 \pm 19.62$ vs. $89.47 \pm 21.86 \%$ of pred.; $P=0.015)$, forced expiratory volume in one second $\left(\mathrm{FEV}_{1}\right)(68.6 \pm 19.93$ vs. $79.4 \pm 21.48$; $P=0.03)$, and total lung capacity (TLC) $(90.6 \pm 15.74$ vs. $104.9 \pm 17.26 \%$ pred.; $P=0.007$ ) compared to patients who had no pneumothorax. More frequently restrictive pattern of respiratory impairment (TLC $<80 \%$ pred.) was noticed in patients with than without pneumothorax (22\% vs. $3 \%$; $P=0.005$ ). Only $12 \%$ of patients had TLC over than $120 \%$ of pred., but in $50 \%$ of patients RV over than $120 \%$ pred. was shown. There were no differences in distribution of patients with symptoms of hyperinflation between patients who had pneumothorax as a initial sign of the PLCH or this without this symptom. The PLCH diagnosis in patients with pneumothorax was established more frequently during the first 
Table 1 Patients characteristics

\begin{tabular}{|c|c|c|c|c|}
\hline & All & $\begin{array}{l}\text { Patients with pneumo- } \\
\text { thorax as the initial sign }\end{array}$ & $\begin{array}{l}\text { Patients without pneumo- } \\
\text { thorax as an initial sign }\end{array}$ & $P$ \\
\hline No. of patients & 90 & $29(32 \%)$ & $61(68 \%)$ & 0.028 \\
\hline Women & $43(48 \%)$ & $9(31 \%)$ & $34(56 \%)$ & \\
\hline Men & $47(52 \%)$ & $20(69 \%)$ & $27(43 \%)$ & \\
\hline \multicolumn{5}{|l|}{ Multisystem } \\
\hline $\mathrm{LCH}$ & $20(22 \%)$ & $4(14 \%)$ & $16(26 \%)$ & 0.185 \\
\hline PLCH & $70(78 \%)$ & $25(86 \%)$ & $45(74 \%)$ & \\
\hline Age (years) & $35.78 \pm 13.24$ & $27.1 \pm 7.92$ & $39.9 \pm 13.21$ & 0.001 \\
\hline Smoking Pack/years (mean \pm SD) & $15.87 \pm 15.14$ & $8.4 \pm 6.85$ & $19 \pm 17.16$ & 0.003 \\
\hline Non-smokers & 2 & 1 & 1 & \\
\hline Smokers & 88 & 28 & 60 & \\
\hline Pneumothoraces during the observation period (Mean; range) & $0.84(0-8)$ & $2.41(1-8)$ & $0.1(0-4)$ & 0.0001 \\
\hline Number of patients with recurrent pneumothoraces & $19(21 \%)$ & $16(55 \%)$ & $3(5 \%)$ & $<0.0001$ \\
\hline Time to diagnosis months $($ mean $\pm \mathrm{SD})$ & $16.87 \pm 28$ & $20.93 \pm 37.5$ & $15.01 \pm 22$ & 0.276 \\
\hline Observation time months (mean \pm SD) & $62.9 \pm 48.61$ & $68.2 \pm 56.96$ & $60.9 \pm 65.22$ & NS \\
\hline Number of patients with diagnosis delay $>12$ months & $33(37 \%)$ & $11(38 \%)$ & $22(36 \%)$ & 0.5 \\
\hline Number of patients with diagnosis delay $<6$ months & $26(29 \%)$ & $13(45 \%)$ & $13(21 \%)$ & 0.036 \\
\hline $\mathrm{FVC} \%$ pred $($ mean $\pm \mathrm{SD})$ & $85.79 \pm 21.38$ & $77.96 \pm 19.62$ & $89.47 \pm 21.86$ & 0.015 \\
\hline $\mathrm{FEV}_{1} \%$ pred $($ mean $\pm \mathrm{SD})$ & $76.06 \pm 21.38$ & $68.6 \pm 19.93$ & $79.4 \pm 21.48$ & 0.03 \\
\hline $\mathrm{FEV}_{1} \% \mathrm{VC}<70 \%$ pred & $19(22 \%)$ & $6(22 \%)$ & $13(22 \%)$ & 0.95 \\
\hline $\mathrm{DL}_{\mathrm{CO}} \%$ pred $($ mean $\pm \mathrm{SD})$ & $59.22 \pm 15.62$ & $60.8 \pm 11.31$ & $58.5 \pm 17.4$ & 0.88 \\
\hline TLC $\%$ pred (mean \pm SD) & $100.2 \pm 17.83$ & $90.6 \pm 15.74$ & $104.9 \pm 17.26$ & 0.007 \\
\hline TLC $>120 \%$ pred & $10(12 \%)$ & $2(7 \%)$ & $8(16 \%)$ & 0.41 \\
\hline TLC $<80 \%$ pred & $8(9 \%)$ & $6(22 \%)$ & $2(3 \%)$ & 0.005 \\
\hline $\mathrm{RV} \%$ pred (mean $\pm \mathrm{SD})$ & $128.55 \pm 42.2$ & $126.15 \pm 25.91$ & $129.66 \pm 48.31$ & 0.36 \\
\hline $\mathrm{RV}>120 \%$ pred & $44(51 \%)$ & $14(52 \%)$ & $30(51 \%)$ & 0.93 \\
\hline $\mathrm{RV}<80 \%$ pred & $5(6 \%)$ & $1(4 \%)$ & $4(7 \%)$ & NS \\
\hline $\mathrm{PaO}_{2} \mathrm{mmHg}($ mean $\pm \mathrm{SD})$ & $78.2 \pm 9.48$ & $80.77 \pm 9.22$ & $77 \pm 9.52$ & 0.89 \\
\hline
\end{tabular}

$F V C$ forced vital capacity, $F E V 1$ forced expiratory volume in $1 \mathrm{~s}, T L C$ total lung capacity, $R V$ residual volume, $D L_{C O}$ diffusion lung capacity for carbon monoxide, $\mathrm{PaO}_{2}$ partial pressure of oxygen in the arterialized blood, $L C H$, Langerhans cell histiocytosis, $P L C H$ pulmonary Langerhans cell histiocytosis, pred. predicted, $S D$ standard deviation

6 months after this episode than in those without it (45\% vs. $21 \% ; P=0.036$ ) (Table 1). During the time of observation, patients who had pneumothorax as the initial sign had more frequently recurrent episodes of this condition, than those who did not have pneumothorax at presentation (55\% vs. 5\%;P<0.001).

Persistent air leakage resulted in subsequent surgical procedures in four patients $(14 \%)$ in the ND group $(P=0.007)$. Recurrent pneumothoraces were more frequent in the D group than in the ND group $(82 \%$ vs. $39 \% ; P=0.02)$ and were observed 1-72 (mean $32 \pm 28.82$ ) months after the first episode. In addition, patients with a delayed diagnosis experienced more recurrences than those with a prompt diagnosis (3.45 vs. $1.78 ; P=0.019$; Table 2 ). CT was performed at the time of first presentation of pneumothorax in all of the patients in the ND group, but in no case in the D group $(P=0.0009)$. An incorrect initial diagnosis caused very long delays in diagnosis in three patients: two men without pneumothorax (diagnosis delay 120 months) were originally diagnosed with hypersensitivity pneumonitis and autoimmune hepatitis, and one woman with pneumothorax as the initial sign (diagnosis delay 176 months) was diagnosed with lymphangioleiomyomatosis. Patients with pneumothorax with a delayed diagnosis had similar pulmonary function as those with a prompt diagnosis (Table 3).

In observed group of patients, 75 (70 in patients with pneumothorax as an initial sign, and five in patients without pneumothorax at the beginning of the disease) episodes of pneumothorax (42 on the left side, and 31 on the right side) were noticed. Eight patients had bilateral recurrent pneumothoraces. Seventy episodes of pneumothorax were treated with chest tube drainage, and $5(6 \%)$ by posturnal drainage. Ten patients (14\%) had only one episode of pneumothorax, successfully treated with pleural drainage. Persistent air lick, in spite of pleural drainage was shown 10 (14\%) times. Recurrent pneumothorax after the chest tube 
Table 2 Characteristics of the patients with pneumothorax

\begin{tabular}{llll}
\hline & $\begin{array}{l}\text { Patients with a } \\
\text { prompt diagnosis } \\
\text { (ND) }\end{array}$ & $\begin{array}{l}\text { Patients with a } \\
\text { delayed diagnosis } \\
\text { (D) }\end{array}$ & $P$ \\
\hline Patients (number) & 18 & 11 & 0.73 \\
Women & 6 & 3 & \\
Men & 12 & 8 & \\
Age (years, mean \pm SD) & $25.6 \pm 8.02$ & $29.55 \pm 7.46$ & 0.15 \\
Smoking (pack/years, mean \pm SD) & $6.22 \pm 6.89$ & $11.09 \pm 5.95$ & 0.026 \\
Number of patients with multiple pneumothoraces & $7(39 \%)$ & $9(82 \%)$ & 0.02 \\
Mean number of pneumothoraces (range) & $1.78(1-6)$ & $3.45(1-8)$ & 0.019 \\
Dyspnoea & $10(56 \%)$ & $9(82 \%)$ & 0.15 \\
Weakness & $11(61 \%)$ & $11(100 \%)$ & 0.5 \\
Chest pain & $8(44 \%)$ & $5(45 \%)$ & 0.7 \\
Sweat & $1(6 \%)$ & $1(9 \%)$ & NS \\
Fever & $1(6 \%)$ & 0 & NS \\
Weight lose & $5(28 \%)$ & $6(55 \%)$ & 0.15 \\
Cough & $13(72 \%)$ & $11(100 \%)$ & 0.036 \\
\hline
\end{tabular}

$S D$ standard deviation, $N S$ non-significant
Table 3 Pulmonary function tests in PLCH patients with pneumotho$\operatorname{rax}$

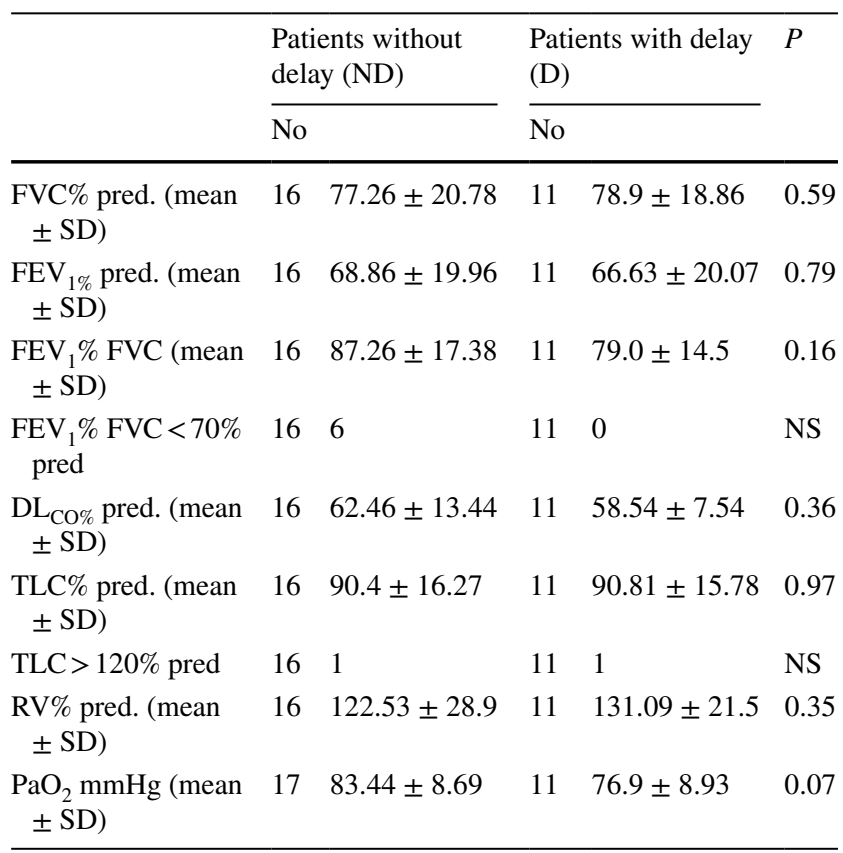

$F V C$ forced vital capacity, FEV1 forced expiratory volume in $1 \mathrm{~s}$, $T L C$ total lung capacity, $R V$ residual volume, $D L_{C O}$ diffusion lung capacity for carbon monoxide, $\mathrm{PaO}_{2}$ partial pressure of oxygen in the arterialized blood, pred. predicted, $S D$ standard deviation

drainage was noticed $50(71 \%)$ times. Mechanical pleurodesis were performed $7(10 \%)$ times, and chemical pleurodesis $3(4 \%)$ times. 37 (53\%) episodes of recurrent pneumothorax were noticed in a month, $6(9 \%)$ in a period of 2-3 months, and $4(7 \%)$ after 1 year. Reactivation of the disease after 2 , and after 7 years was connected with pneumothorax in one patient and in two patients, respectively. Ipsilateral recurrence of pneumothorax was noticed $33(66 \%)$ times and recurrence to the contralateral side 17 (34\%) times. Recurrent pneumothoraces in a month and in other case after 4 months from the mechanical pleurodesis were observed. Chemical pleurodesis was ineffective in one patient, and recurrence of pneumothorax was observed after a month from this procedure. Seven years after the mechanical and chemical pleurodesis in the course of PLCH progression pneumothorax was observed in two patients. Recurrent pneumothoraces were observed more frequently in patients with multisystem disease, than in those with isolated PLCH ( $45 \%$ vs. $15 \% ; P=0.005$ ).

Patients were under the observation for a mean time of $62.9 \pm 48.61$ months, and three were no significant differences between groups in the time of follow-up (Table 1).

\section{Discussion}

We found that patients who had pneumothorax as a first sign of PLCH were younger, more frequently men, smoked fewer cigarettes, and had greater respiratory impairment than patients who did not have pneumothorax at presentation.

Pneumothorax is a very important and suggestive sign of cystic lung disease [10-12]. Pneumothorax caused by PLCH accounts for $0.25-0.5 \%$ of all spontaneous pneumothoraces each year in the United States [20]. The frequency of patients who have pneumothorax as the initial sign of PLCH ranges widely from 10 to $32 \%$ in different patient cohorts [4, 6, 9, 12-15]. As in Mendez et al., our patients with PLCH who 
experienced pneumothorax were more frequently younger men; however, Mendez et al. did not observe more severe respiratory impairment in patients with pneumothorax, contrary to the patients in our study [9]. About $20 \%$ of the our PLCH patients experienced recurrent pneumothoraces, which were more frequent in patients who had pneumothorax at the beginning of the disease, which potentially had a negative influence on pulmonary function at the time of presentation. A multicentre, prospective, observational study of $58 \mathrm{PLCH}$ patients conducted in France found that 19\% of patients had history of pneumothorax and two patients who experienced pneumothorax during follow-up [12]. Additionally, it was shown that smoking status and $\mathrm{PaO}_{2}$ were risk factors for lung function deterioration during the first years after diagnosis. This study proved that smoking cessation is the most important recommendation for PLCH patients [12]. Therefore, a prompt diagnosis is very important; however, less than $50 \%$ of patients with PLCH give up this addiction, in spite of diagnosis [16-19]. About $70 \%$ of our patients stated that they had quit smoking, but this was not proven objectively.

All of our patients who underwent HRCT at the time of first pneumothorax were diagnosed correctly. No patients who were diagnosed more than 12 months after pneumothorax underwent HRCT. A routine chest X-ray has very limited sensitivity and specificity for detecting cystic lesions in the lungs compared to CT. Recently, Gupta et al. showed that HRCT is cost-effective for screening for rare cystic lung diseases, such as Birt-Hogg-Dubé syndrome, LCH, and lymphangioleiomyomatosis, in patients with spontaneous pneumothorax, despite the fact that the prevalence of these diseases is lower than $0.01 \%$ [20].

We believe that CT should be used to assess patients with spontaneous pneumothorax, as it is not only very sensitive, but is also cost-effective for diagnosing rare cystic lung diseases. Experience with low-dose CT in patients with pulmonary nodules suggests that this examination can be used with other indications, including multicystic lung diseases. Low-dose CT has a lower sensitivity for detecting interstitial lesions than standard-dose CT, but the exposure dose is significantly lower (1.5 vs. $7 \mathrm{msv}$ ) [21, 22]. Therefore, we suggest the recommendation of the low-dose chest CT in all patients with spontaneous pneumothorax.

Our patients were mainly treated with chest tube drainage, which was successful in distance of a year in $14 \%$ of cases. In a period of 1 year, mechanical pleurodesis was effective in $71 \%$ patients and chemical in $66 \%$ patients, but in a long observation, additional recurrent pneumothoraces were noticed. On contrary, Mendez et al reported that surgical management of pneumothorax was very effective, and no case of recurrent pneumothorax was noticed after pleurodesis [9]. In our patients, recurrent pneumothorax occurred mainly at the beginning of the disease (during the first month), in active phase of PLCH or in the time of relapse.
In addition, patients with multisystem rather than isolated PLCH had recurrent pneumothoraces more frequently (45\% vs. $15 \% ; P=0.005)$. This finding also supports link between active disease and pneumothorax. There were no patients who had mechanical or chemical pleurodesis during the management of the first episode of pneumothorax. Those patients were treated mainly in district hospital, on usual surgery departments, in which chest tube drainage was preferred. Due to high rate of recurrence, pleurodesis is advised following the initial episode of pneumothorax, but before patients should be diagnosed. Regarding this recommendation, CT scan in patients with pneumothorax should be performed at the initial episode of pneumothorax [20].

There were some limitations to this study. It was a retrospective, single-centre study. The presented pulmonary function parameters were the first measurements performed in our hospital. The patients were referred after different lengths of time from the first sign of PLCH, or even from diagnosis, therefore it might influence on results of pulmonary function. In patients who had a pneumothorax as the first sign of the disease, the PFTs were done 3-6 months after this episode. Lower values of pulmonary function test in patients, who had a history of pneumothorax might be connected with pleural lesions caused by pleural derange, pleurodesis, or pleurectomy. From the other side, more than $50 \%$ of patients who did not have pneumothorax as an initial symptom had videoassisted thoracoscopy (usually in regional hospitals) for PLCH diagnosis, and it might also influence slightly lower PFTs parameters in those patients, measured in the time of first presentation in our hospital.

Nevertheless, the focus of this study was to underline the role of chest $\mathrm{CT}$ in the rapid, correct diagnosis of PLCH, because it is translated into better outcomes for these young patients.

\section{Conclusion}

Patients who had pneumothorax as the first sign of PLCH were more frequently men, younger, smoked more intensively, experienced recurrent pneumothoraces, and had greater respiratory impairment than patients who had no pneumothorax. Chest $\mathrm{CT}$ in patients with pneumothorax led to a prompt diagnosis of PLCH and CT should be performed in all young patients with spontaneous pneumothorax. Recurrent pneumothorax is a symptom of active disease.

Acknowledgements The authors express thanks to the Doctors Jerzy Bogdan, Paweł Caban, Mariusz Chabowski, Juliusz Gątarek, Bożena Graca, Agnieszka Jarzemska, Dariusz Jastrzębski, Tomasz Kachel, Wojciech Naumnik who referred the patients.

Author Contributions ER helped to conceive, design, coordinate, analyse and interpret the data, and draft the manuscript. KB-P and RL 
helped to acquire the data and draft the manuscript. EW and KR-S helped to coordinate the study, acquire the data and draft the manuscript. All of the authors read and approved the final manuscript.

Funding The study was supported by Grant Number 7.09 from the National Tuberculosis and Lung Diseases Research Institute, and was approved by the local bioethics committee.

\section{Compliance with Ethical Standards}

Conflict of interest All of the authors have declared that they have no competing interests.

Open Access This article is distributed under the terms of the Creative Commons Attribution 4.0 International License (http://creativeco mmons.org/licenses/by/4.0/), which permits unrestricted use, distribution, and reproduction in any medium, provided you give appropriate credit to the original author(s) and the source, provide a link to the Creative Commons license, and indicate if changes were made.

\section{References}

1. Emile J-F, Abla O, Fraitag S et al (2016) Revised classification of histiocytoses and neoplasms of the macrophage-dendritic cell lineages. Blood 127:2672-2681

2. Vaiselbuh SR, Bryceson YT, Allen CE, Whitlock JA, Abla O (2014) Updates on histiocytic disorders. Pediatr Blood Cancer 61:1329-1335

3. Girschikofsky M, Arico M, Castillo D et al (2013) Management of adult patients witch Langerhans cell histiocytosis: recommendations from an expert panel on behalf of Euro-Histio-Net. Orphanet J Rare Dis 8:1-11

4. Vassalo R, Ryu JH, Schroeder DR et al (2002) Clinical outcomes of pulmonary Langerhans cell histiocytosis in adult. N Engl J Med 346:484-490

5. Tazi A (2006) Adult pulmonary Langerhans cell histiocytosis. Eur Respir J 27:1272-1285

6. Arico M, Girschikofsky M, Genéreau T et al (2003) Langerhans cell histiocytosis in adults: report from the International Registry of the Histiocyte Society. Eur J Cancer 39:2341-2348

7. Radzikowska E (2017) Pulmonary Langerhans cell histiocytosis in adults. Adv Respir Med 85:277-289

8. Odame I, Li P, Lau L et al (2006) Pulmonary Langerhans cell histiocytosis: a variable disease in childhood. Pediatr Blood Cancer 47:889-893
9. Mendez JL, Nadrous HF, Vassallo R, Decker PA, Ryu JH (2004) Pneumothorax in pulmonary Langerhans cell histiocytosis. Chest 125:1028-1032

10. Tschopp JM, Bintcliffe O, Astoul P et al (2015) ERS task force statement: diagnosis and treatment of primary spontaneous pneumothorax. Eur Respir J 46:321-335

11. Hallifax RJ, Rahman NM (2015) Epidemiology of pneumothorax: finally something solid out of thin air. Thorax 70:921-922

12. Tazi A, de Margerie C, Naccache JM et al (2015) The natural history of adult pulmonary Langerhans cell histiocytosis: a prospective multicentre study. Orphanet J Rare Dis 10:30

13. Elia D, Torre O, Cassandro R, Caminati A, Harari S (2015) Pulmonary Langerhans cell histiocytosis: a comprehensive analysis of 40 patients and literature review. Eur J Intern Med 26:351-6.10

14. Bernstrand C, Cederlund K, Sandstedt B et al (2001) Pulmonary abnormalities at long-term follow-up of patients with Langerhans cell histiocytosis. Med Pediatr Oncol 36:459-468

15. Schönfeld N, Dirks K, Costabel U, Loddenkemper R (2012) A prospective clinical multicentre study on adult pulmonary Langerhans' cell histiocytosis. Sarcoidosis Vasc Diffuse Lung Dis 29:132-138

16. Mogulkoc N, Veral A, Bishop PW et al (1999) Pulmonary Langerhans' cell histiocytosis: radiologic resolution following smoking cessation. Chest 115:1452-1455

17. Negrin-Dastis S, Butenda D, Dorzee J, Fastrez J, d'Odémont JP (2007) Complete disappearance of lung abnormalities on highresolution computed tomography: a case of histiocytosis X. Can Respir J 14:235-237

18. Tazi A, Montcelly L, Bergeron A, Valeyre D, Battesti JP, Hance AJ (1998) Relapsing nodular lesions in the course of adult pulmonary Langerhans cell histiocytosis. Am J Respir Crit Care Med 157:2007-2010

19. Tazi A, Marc K, Dominique S et al (2012) Serial computed tomography and lung function testing in pulmonary Langerhans' cell histiocytosis. Eur Respir J 40:905-912

20. Gupta N, Langenderfer D, McCormack FX, Schauer DP, Eckman MH (2017) Chest computed tomography image screening for cystic lung diseases in patients with spontaneous pneumothorax is cost effective. Ann Am Thorac Soc 14:17-25

21. Christe A, Charimo-Torrente J, Roychoudhury K, Vock P, Roos JE (2013) Accuracy of low-dose computed tomography (CT) for detecting and characterising the most common CT-patterns of pulmonary disease. Eur J Radiol 82:e142-e150

22. Radiological Society of North America (2016) Radiation dose in X-Ray and CT exams. http://www.radiologyinfo.org/en/info. cfm?pg=safery-Xray. Accessed 26 Apr 2016 